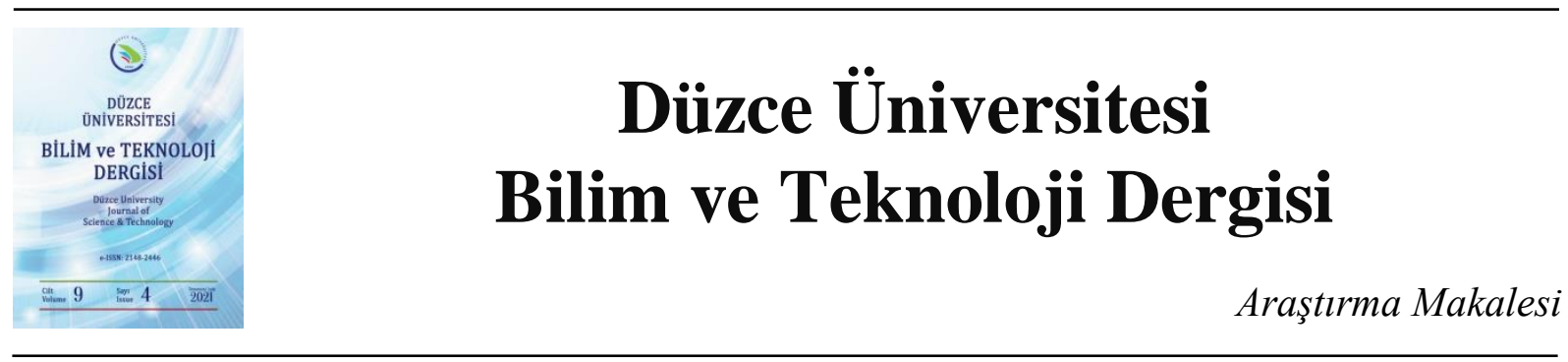

\section{Doğanşehir-Eskiköy (Malatya) Bölgesindeki Neojen Yaşlı (?) Volkanik Kayaçların Petrografik, Jeokimyasal ve Petrolojik Özellikleri}

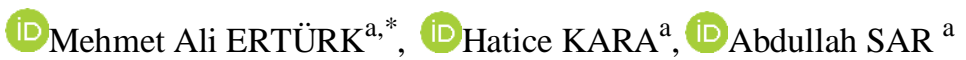 \\ ${ }^{a_{J}}$ eoloji Mühendisliği Bölümü, Mühendislik Fakültesi, Fırat Üniversitesi, Elazı̆̆, TÜRKİYE \\ * Sorumlu yazarın e-posta adresi: erturkmae@ gmail.com
} DOI:10.29130/dubited.887363

\begin{abstract}
$\underline{O ̈ Z}$
Bu çalışmada Eskiköy-Doğanşehir (Malatya) bölgesindeki Neojen (?) yaşlı volkanik kayaçlarının petrografik ve jeokimyasal özellikleri incelenmiştir. Çalışma bölgesi Permo-Triyas yaşlı Malatya metamorfitleri, Üst Kretase yaşlı Berit ofiyoliti, Erken-Orta Eosen yaşlı Doğanşehir, Polat-Beğre granitoidi, Neojen (?) yaşlı volkanitler ve Plio-Kuvaterner yaşlı alüvyonlardan oluşmaktadır. İncelenen volkanik kayaçlar Permo-Triyas yaşlı Malatya metamorfik kayaçlarını sıcak dokanakla keserek yüzeylemişlerdir. Dasit ve riyolit bileşimindeki volkanitler başlıca plajiyoklas, sanidin, kuvars, biyotit ve amfibol minerallerinden oluşurlar. Söz konusu volkanitler kalkalkali ve yüksek-K kalk-alkali karaktere sahiptirler. Primitif mantoya normalize edilmiş çoklu element ve kondrite normalize edilmiş nadir toprak element değişim diyagramında büyük iyon yarıçaplı litofil elementleri ve hafif nadir toprak elementleri zenginleşme göstermektedir ve yitime bağlı olarak okyanusal kabuktan türeyen çözeltiler tarafından metasomatize edilmiş bir mantodan kaynaklandığı düşünülmektedir.
\end{abstract}

Anahtar Kelimeler:Jeokimya, Malatya, Neojen volkanitleri, Petrografi

\section{Petrographic, Geochemical and Petrological Characteristics of Neogene (?) Volcanicsin the Doğanşehir-Eskiköy (Malatya) Region}

\begin{abstract}
In this study, petrographic and geochemical properties of Neogene (?)volcanic rocks in Eskiköy-Doğanşehir (Malatya) region were investigated. The study area consists of Permo-Triassic Malatya metamorphics, Late Cretaceous Berite ophiolite, Early-Middle Eocene Doğanşehir, Polat-Beğre granitoids, Neogene (?) volcanics, and Plio-Quaternary alluviums. The investigated volcanic rocks exposed the Permo-Triassic Malatya metamorphic rocks by cutting with hot contact. Volcanics in dacite and rhyolite composition mainly consist of plagioclase, sanidine, quartz, biotite and amphibole minerals. These volcanics have calc-alkali and high-K calcalkali characters. In the primitive mantle normalized multi-element and chondrite-normalized rare earth element variation diagram, large ion lithophile elements and light rare earth elements show enrichment and are thought to be caused by a mantle metasomatized by solutions derived from the oceanic crust due to subduction.
\end{abstract}

Keywords:Geochemistry,Malatya, Neogene volcanics, Petrography

Geliş: 26/02/2021, Düzeltme:29/04/2021, Kabul: 04/05/2021 


\section{GIRIS}

Torid-Anatolid Platformu ile Arap Platformu arasında yer alan Güneydoğu Anadolu Orojenik Kuşağı, Alp-Himalaya sisteminin en karmaşık segmentlerinden biridir[1-3]. Toridler, Alp-Himalaya dağ oluşum kuşağının bir parçasıdır ve sürekli fakat düzgün olmayan bir kuşak olarak Batı Anadolu'dan Akdeniz kıyısına paralel olarak uzanıp, Doğu ve Güney Anadolu'da ise kuzeydoğudan doğu-batıya ve güneydoğuya dönen bir yay oluşturur. Doğu Anadolu Bölgesi (DAB), Torid-Anatolid platformunun doğusunda, neotektonik dönemde tanımlanan bir kuşaktır [4-5]. Bu kuşak, Şengör [1] tarafından Doğu Anadolu Sıkışma Bölgesi olarak tanımlanmıştır. Pearce vd. [6], Arap ve Anadolu levhalarının çarpışması sonucu geliştiği için bu kuşağı Doğu Anadolu Çarpışma Zonu olarak adlandırmıştır. DAB'ın jeodinamiği ve volkanik evrimi günümüzde halen tartışmalı bir konu olup, bölgede volkanik faaliyetin Miyosen'de neotektonik dönem ile başladığı düşünülmektedir [4]. Volkanlar çoğunlukla açılma çatlaklarını kendilerine çıkış yolu olarak belirlemiş ve yeryüzüne yerleşmişlerdir. DAB'da bu döneme ait geniş çökelme ortamları ve bu çökellerle eş yaşlı olarak, geniş alanlı yüzeylemeler gösteren volkanitler yer almaktadır. Son yıllarda Doğu Anadolu'da çarpışma sonrası volkanizmanın özelliklerini ortaya koyabilmek için dizi jeokimyasal, petroloji ve jeokronoloji çalışmaları yapılmıştır [7]-[22].

İnceleme alanında yüzeyleyen volkanik birimler Doğanşehir-Eskiköy (Malatya) yöresinde Doğu Toros Orojenik Kuşağı'nda Alanya Birliği içerisinde yer almaktadır. Bu çalışma Doğanşehir-Eskiköy (Malatya) bölgesinde yüzeyleyen volkanik kayaçlar için petrografik bulgular ve yeni tüm kayaç ana oksit ve iz element jeokimyası verilerini sunmayı hedeflemiştir. Bu çalışma ile (i) magma kaynak alanı (ii) fraksiyonel kristalleşme ve kabuksal kirlenme (iii) tektonik ortam gibi konular ışığında inceleme alanındaki volkanik kayaçların petrojenezinin ortaya çıkarılması amaçlanmıştır.

\section{JEOLOJIKK KONUM}

İnceleme alanında Paleozoik, Mezozoik, Senozoik yaşlı kaya toplulukları ayırtlanmıştır. Buna göre çalışma alanı kronostratigrafik olarak yaşlıdan gence doğru Permo-Triyas yaşlı Malatya metamorfikleri, Üst Kretase yaşlı Berit ofiyoliti, Erken-Orta Eosen yaşlı Doğanşehir, Polat-Beğre granitoidi, Neojen (?) yaşlı volkanitler, ve Plio-Kuvaterner yaşlı alüvyonlardan oluşmaktadır (Şekil 1). Malatya metamorfitleri bölgede allokton olarak bulunmaktadır. Permo-Triyas yaşlı kabul edilen Malatya metamorfitleri, inceleme alanında alttan üste doğru genellikle şist (mikaşist, kuvarsserizitşist), fillit, dolomit, mermer ve kristalize kireçtaşlarından oluşan bir istif sunmaktadır [23]-[25]. Birim çalışma alanında kronostratigrafik olarak en yaşı birim olmasına rağmen naplar oluşturan tektonik hareketlerin bir sonucu olarak çalışma alanında en üstte yer almaktadır [26]. Birimin üst dokanağı gözlenememektedir. Çalışma alanında alt dokanağında Berit metaofiyoliti ve granitoidler bulunmaktadır. Alttaki birimlerle olan dokanağı tektoniktir. Granitoidler ile olan dokanağı kimi yerde tektonik, kimi yerde ise intrüziftir. Malatya ve Keban metamorfitleri Geç Kretase'de ofiyolitlerin üzerine kuzeyden güneye bindirmiştir [27-28]. Malatya metamorfitleri Üst Kretase'de metamorfizmaya uğramıştır [29]. Berit ofiyoliti, serpantinleşmiş dunit ve harzburjitlerden meydana gelen ultramafik kayaçlar, gabrolar ve bunları kesen verlitik damarlardan oluşmuştur. Berit ofiyolitik kayaçları, Neotetis'in güney kolunun Üst Kretase'den itibaren kuzeye doğru dalması ve dalan levhanın üzerinde kalan okyanusal levhada oluşan açılma (Supra-subduction zone) ile oluşmuşlardır [30]. Çalışma alanının batı bölgesinde geniş alanlarda yüzeyleyen Polat, Beğre ve Doğanşehir gibi farklı isimlerle adlandırılmış granitoidler bulunmaktadır. Önal [24]'a göre Polat-Beğre granitoidleri adlaması kullanılan birim diyorit, kuvars diyorit, tonalit, granodiyorit ve kuvars monzodiyoritlerden meydana gelen derinlik kayaçlarından oluşmaktadır. Ayrıca bu kayaçlar, mikrodiyorit, diyoritporfir, tonalitporfir, aplit, lamprofir ve nadir olarak görülen andezitik dayklar tarafindan kesilmiş olduğundan bahsetmiştir. Karaoğlan [26]'e göre Doğanşehir granitoidi adlaması kullanılan birim amfibollü gabro, diyorit, kuvars diyorit, tonalit, granodiyorit, mafik dayklar ve felsik dayklardan oluşmaktadır. I-tipi kalkalkalen bir magma özelliği gösteren Doğanşehir granitoidinin aktif kıta kenarında oluşan bir 
volkanik yay granitoidi olduğu önerilmektedir [24-26]. Doğanşehir granitoyidi zirkon U-Pb yaşlandırmasına göre 50.8-45.7 My. arasında (Erken-Orta Eosen) oluştuğu tespit edilmiştir [31]. İnceleme alanında çalışmanın asıl konusunu oluşturan volkanitler daha önceki çalışmalarda Orta Eosen yaşlı Maden Karmaşı̆̆ı' na dâhil edilmişlerdir. Birim Malatya metamorfitlerini genişliği yer yer 5-10 metreyi bulan dayklar halinde kesmiştir. İncelenen kayaçlar, Maden Karmaşı̆̆g'na [32-33] ait volkanitlerin mineralojik ve jeokimyasal verileri ile kıyaslandığında hem alterasyon bakımından hem de jeokimyasal olarak farklı olduğu sonucuna varılmıştır. İncelenen kayaçların stratigrafik ilişkileri, petrografi ve jeokimyasal özellikleri dikkate alındığında Maden Karmaşı̆̆ı'na dâhil edilmemesi gerektiği anlaşılmıştır. Birim Neojen (?) yaşlı olduğu düşünülmekte olup Doğu Toroslar'da yüzeyleyen Neojen yaşlı volkanik kayaçlar ile deneştirilebilir. İnceleme alanında yer alan PlioKuvaterner yaşlı birimler alüvyonlardan meydana gelmektedir.

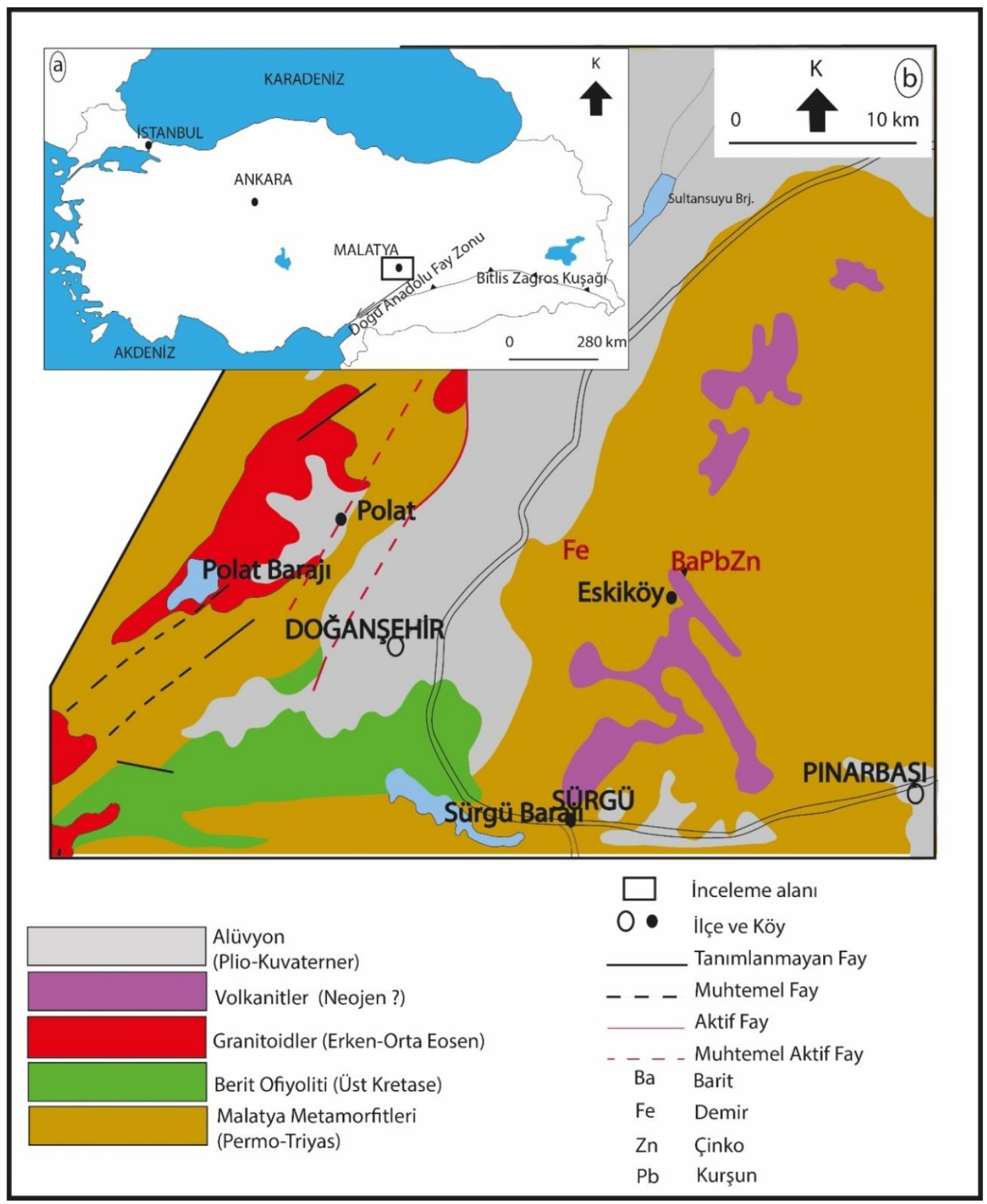

Şekil 1. Çalışma alanı yer bulduru ve jeoloji haritası (MTA [34]'dandeğiştirilmiştir) 


\section{MATERYAL VE METOT}

Arazi çalışmaları kapsamında alınan örneklerin, petrografik ve jeokimyasal incelemeleri gerçekleştirilmiştir. Petrografik amaçlı ince kesitleri Fırat Üniversitesi, Jeoloji Mühendisliği Bölümü Laboratuvar'ında hazırlanmıștır. Hazırlanan kesitler polarizan mikroskop altında ayrıntılı olarak incelenerek kayaçların mineralojik bileşimleri, petrografik ve dokusal özellikleri belirlenmiştir. Petrografi incelemelerine göre 6 adet taze volkanik kayaç örneği üzerinde ICP-AES ve ICP-MS yöntemi kullanılarak ana oksit, iz ve nadir toprak element analizleri Bureau Veritas Minerals Laboratuvar'ında (Vancouver-Kanada) yaptırılmıştır.

\section{BULGULAR}

\section{A. PETROGRAFi}

Eskiköy-Doğanşehir çevresinde yüzeyleyen volkanik birimler dasit ve riyolit türü kayaçlarla temsil edilmektedir (Şekil 2a, b). Dasitler makroskobik olarak grimsi renklerde görülmekte ve porfirik doku göstermektedir (Şekil 2c). Bileşimsel olarak \% 35 plajiyoklas, \% 25 kuvars, \% 10 biyotit+amfibol, plajiyoklas+biyotit mikrolitleri ve camsı malzeme içeren hamur malzemesinden oluşmaktadır. Plajiyoklaslar genellikle iri fenokristaller şeklinde öz şekilli ve yarı özşekilli prizmatik kristaller halinde olmasına rağmen, bu kristallerin arasını dolduran mikrolitler şeklinde de görülmektedir. Albit ve karlsbad ikizlenmeleri gözlenmektedir. Bazı plajiyoklas kristallerinde zonlanma görülmektedir.Plajiyoklas fenokristallerinde gözlenen salınımlı zonlanma ve erime çözünme yapıları magma karışımı ve/veya magmanın hızlı yükselmesine işaret etmektedir.Kayaç genelinde az-orta düzeyde serizitik alterasyon gözlenmektedir. Kuvarslar özşekilsiz formlarda olup dalgalı sönme göstermektedir. Kahverengi pleokroizmaları ile karakteristik olan biyotitler, öz şekilli ve yarı özşekilli, levhams1- prizmatik kristaller halinde gözlenmektedir ve tek yönde dilinimlere sahip olup paralele yakın (yaklaşık $5^{\circ}$ ) sönme göstermektedir (Şekil 2d). Riyolitler bileşimsel olarak \% 15 kuvars, \% 20 sanidin \% 25 plajiyoklas \% 10 biyotit+amfibol ve \% 30 kuvars+plajiyoklas mikrolitleri ve cams1 malzeme içeren hamur malzemesinden oluşmaktadır. Makroskobik olarak pembemsi renklerde olupporfirik doku göstermektedir. Kuvarslar, çoğunlukla özşekilsiz kristaller halindedir. Sanidinler yarı özşekilli ve özşekilsiz kristaller halinde gözlenmekte olup karlsbad ikizlenmeleri ile karakteristiktir. Plajiyoklaslar, öz şekilli ve yarı özşekilli kristaller halindedir, albit ve karlsbad ikizlenmeleri göstermektedir.Uzun levhamsı kristaller şeklinde gözlenen biyotitler çoğunlukla özşekilli formlarda görülmektedir. Bazı biyotit minerallerinde kloritleşmeler gözlenmektedir.Altıgen formlara sahip amfiboller, genel olarak yarı özşekilli ve özşekilli olup mineral kapantıları içermektedir. 


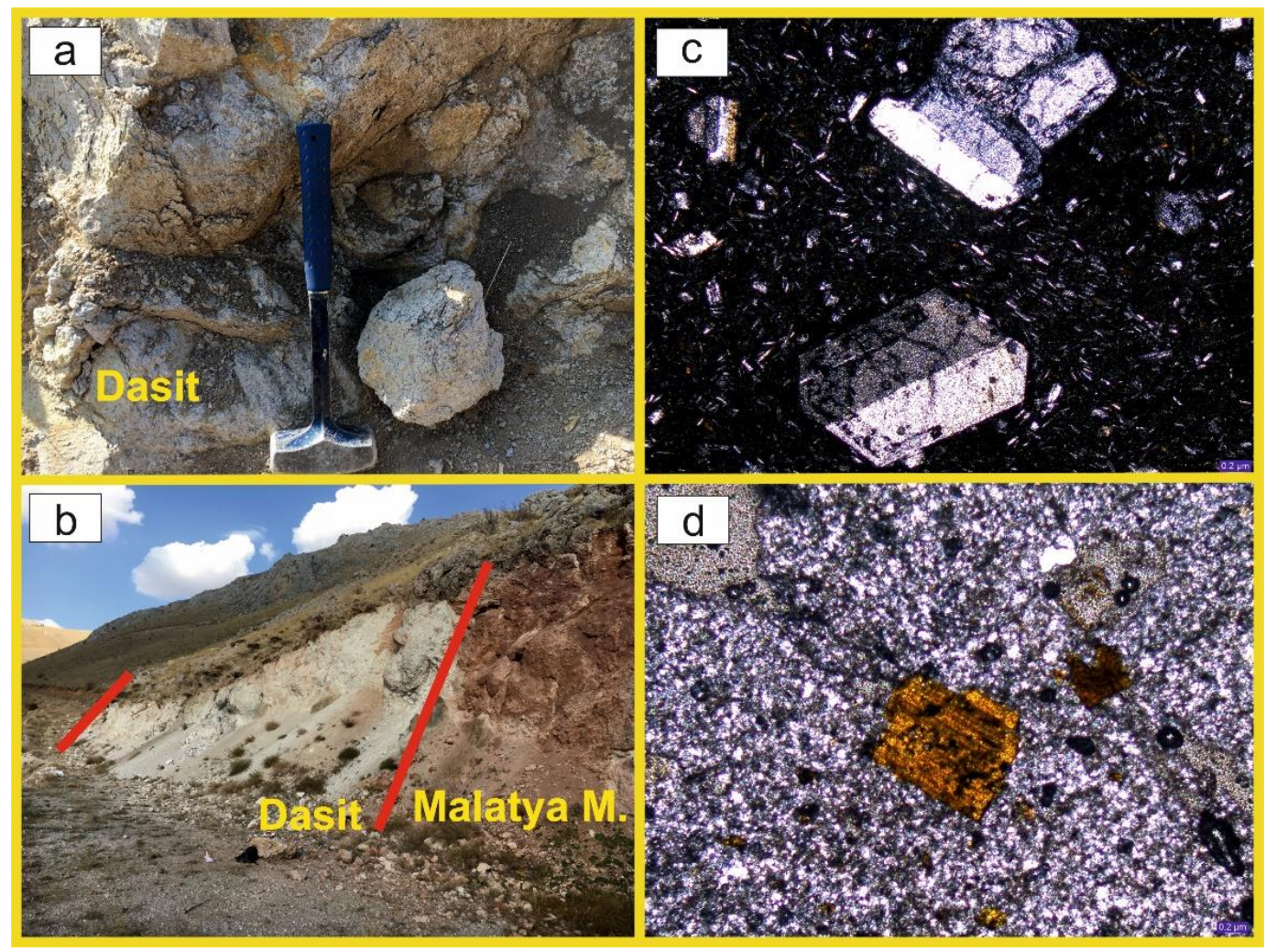

Şekil 2.İncelenen volkanitlerin arazi iliş̧kileri $(\boldsymbol{a}, \boldsymbol{b})$, ince kesit görüntüleri $(\boldsymbol{c}, \boldsymbol{d})$

\section{B. JEOKIMMYA}

Doğanşehir-Eskiköy bölgesinde volkanit kayaçlara ait 6 örnek üzerinde tüm kayaç analiz sonuçları Tablo 1'de verilmiştir.İncelenen volkanik kayaçlar $\mathrm{SiO}_{2}$ 'ye karşı $\mathrm{Na}_{2} \mathrm{O}+\mathrm{K}_{2} \mathrm{O}$ [35] sınıflama diyagramında dasit ve riyolit alanına düşmektedir (Şekil 3).Bu sonuçlar arazi ve petrografi gözlemleriyle uyumluluk göstermektedir.Peccerillo ve Taylor [36] tarafindan hazırlanmış olan $\mathrm{SiO}_{2-}$ $\mathrm{K}_{2} \mathrm{O}$ değişim diyagramında incelenen örnekler kalk-alkali ve yüksek-K kalk-alkali alanlarında yoğunlaşmışlardır (Şekil 4). İncelenen volkanik kayaçlar primitive mantoya normalize edilmiş çoklu element değişim diyagramlarına göre büyük iyon yarıçaplı litofil elementler (LILE), yüksek alan enerjili elementlere göre (HFSE) daha fazla zenginleşme göstermektedir (Şekil 5a). Kondrite normalize edilmiş nadir toprak element değişim diyagramında hafif nadir toprak elementler (HNTE), ağır nadir toprak elementlere göre (ANTE) daha fazla zenginleşme göstermektedir (Şekil 5b). $\mathrm{SiO}_{2}$ 'ye karşı çizilmiş ana oksit değişim diyagramlarında $\mathrm{Al}_{2} \mathrm{O}_{3}, \mathrm{MgO}, \mathrm{CaO}, \mathrm{Na}_{2} \mathrm{O}, \mathrm{P}_{2} \mathrm{O}_{5}, \mathrm{TiO}_{2}$ ve $\mathrm{FeO}_{(\mathrm{t})}$ ile negatif korelasyon gösterirken, $\mathrm{K}_{2} \mathrm{O}$ ile ise pozitif korelasyon göstermektedir (Şekil 6). $\mathrm{SiO}_{2}$ 'ye karş1 çizilmiş iz element değişim diyagramlarında ise $\mathrm{Sr}$, Ba, Co, $\mathrm{Hf}, \mathrm{Zr}$ ve Ce ile negatif korelasyon görülürken, $\mathrm{Rb}$ ve Th ile ise pozitif korelasyon görülmektedir (Şekil 7). 
Tablo 1.Incelenen kayaçların ana oksit ve iz element değerleri

\begin{tabular}{|c|c|c|c|c|c|c|}
\hline $\begin{array}{c}\text { Kayaç } \\
\text { Türü }\end{array}$ & Dasit & Dasit & Dasit & $\underset{t}{\text { Riyoli }}$ & $\underset{t}{\text { Riyoli }}$ & $\underset{t}{\text { Riyoli }}$ \\
\hline Örnek & ES1 & ES2 & ES3 & ES9 & ES10 & ES11 \\
\hline \multicolumn{7}{|c|}{$\begin{array}{c}\text { Major oksitler (\% } \\
\text { ağ. ) }\end{array}$} \\
\hline $\mathrm{SiO}_{2}$ & 66.91 & 66.96 & 68.54 & 71.60 & 73.61 & 73.81 \\
\hline $\mathrm{Al}_{2} \mathrm{O}_{3}$ & 15.40 & 15.89 & 15.66 & 13.59 & 14.27 & 14.11 \\
\hline $\mathrm{Fe}_{2} \mathrm{O}_{3}{ }^{\mathrm{a}}$ & 2.72 & 2.68 & 2.44 & 0.86 & 0.68 & 0.73 \\
\hline MgO & 1.23 & 1.27 & 1.16 & 0.17 & 0.33 & 0.32 \\
\hline $\mathrm{CaO}$ & 3.22 & 3.32 & 3.35 & 0.89 & 0.93 & 0.87 \\
\hline $\mathrm{Na}_{2} \mathrm{O}$ & 3.55 & 3.43 & 3.83 & 3.33 & 3.72 & 3.65 \\
\hline $\mathrm{K}_{2} \mathrm{O}$ & 3.14 & 3.10 & 2.11 & 5.03 & 4.42 & 4.40 \\
\hline $\mathrm{TiO}_{2}$ & 0.40 & 0.41 & 0.37 & 0.07 & 0.08 & 0.1 \\
\hline $\mathbf{P}_{2} \mathrm{O}_{5}$ & 0.12 & 0.11 & 0.10 & 0.02 & 0.02 & 0.03 \\
\hline MnO & 0.05 & 0.04 & 0.03 & 0.05 & 0.02 & 0.0 \\
\hline $\mathrm{Cr}_{2} \mathrm{O}_{3}$ & 0.00 & 0.00 & 0.00 & $\begin{array}{c}<0.00 \\
2\end{array}$ & $\begin{array}{l}<0.00 \\
2\end{array}$ & $\begin{array}{c}<0.00 \\
2\end{array}$ \\
\hline LOI & 3.10 & 2.60 & 2.30 & 4.30 & 1.80 & 1.90 \\
\hline Sum & 99.90 & 99.89 & 99.9 & 100.0 & 99.95 & 99.95 \\
\hline \multicolumn{7}{|c|}{ İz elementler (ppm) } \\
\hline $\mathbf{B a}$ & 393 & 446 & 279 & 140 & 198 & 156 \\
\hline Sc & 5 & 5 & 4.9 & 5 & 2.5 & 2.7 \\
\hline Co & 5.3 & 5.4 & 4.8 & 0.7 & 0.5 & 0.5 \\
\hline Cs & 6.3 & 7 & 4.5 & 26.6 & 17.2 & 15.9 \\
\hline Ga & 16 & 17.8 & $<5$ & 17.5 & $<5$ & $<5$ \\
\hline Hf & 3.5 & 3.7 & 3.6 & 2.2 & 2.3 & 2.4 \\
\hline $\mathbf{N b}$ & 6 & 6.7 & 5.2 & 14.8 & 15.9 & 15 \\
\hline $\mathbf{R b}$ & 90.9 & 94.8 & 73.2 & 212.4 & 225.3 & 218.2 \\
\hline $\mathbf{S r}$ & 258.9 & 275.1 & 232.6 & 45.9 & 41.9 & 38.6 \\
\hline Ta & 0.5 & 0.7 & 0.5 & 2.5 & 2.6 & 2.7 \\
\hline Th & 9.3 & 10 & 6.9 & 12.9 & 14.9 & 13.2 \\
\hline $\mathbf{U}$ & 4.3 & 3.9 & 2.4 & 12.8 & 9.3 & 8.7 \\
\hline $\mathbf{V}$ & 39 & 39 & 41 & $<8$ & $<8$ & $<8$ \\
\hline W & 1.2 & 1.3 & 0.6 & 1.3 & 1.2 & 1.1 \\
\hline $\mathbf{Z r}$ & $\begin{array}{c}134.2 \\
0\end{array}$ & $\begin{array}{c}139.0 \\
0\end{array}$ & $\begin{array}{c}132.7 \\
0\end{array}$ & 42.80 & 48.80 & 46.60 \\
\hline $\mathbf{Y}$ & 12 & 12.6 & 11.9 & 22.1 & 21.3 & 23.5 \\
\hline $\mathbf{P b}$ & 11.80 & 44.20 & 2.60 & 15.80 & 3.50 & 2.40 \\
\hline $\mathbf{N i}$ & 6 & 3.9 & 6.3 & 0.9 & $<0.5$ & 0.8 \\
\hline La & 20.90 & 22.80 & 18.70 & 8.90 & 10.40 & 9.60 \\
\hline $\mathrm{Ce}$ & 38.3 & 41.1 & 33.2 & 18.9 & 21.2 & 18.7 \\
\hline Pr & 4.13 & 4.46 & 3.68 & 2.26 & 2.61 & 2.35 \\
\hline Nd & 14.9 & 17 & 13.6 & 9.5 & 9.8 & 9.2 \\
\hline Sm & 2.86 & 3.23 & 2.64 & 2.97 & 3.23 & 2.96 \\
\hline Eu & 0.78 & 0.79 & 0.72 & 0.37 & 0.39 & 0.37 \\
\hline Gd & 2.74 & 3.15 & 2.4 & 3.56 & 3.63 & 3.56 \\
\hline $\mathbf{T b}$ & 0.4 & 0.43 & 0.35 & 0.66 & 0.68 & 0.68 \\
\hline Dy & 2.17 & 2.5 & 1.99 & 3.86 & 3.77 & 4.12 \\
\hline Но & 0.43 & 0.46 & 0.39 & 0.72 & 0.77 & 0.84 \\
\hline Er & 1.31 & 1.23 & 1.16 & 2.22 & 2.29 & 2.47 \\
\hline $\mathbf{T m}$ & 0.16 & 0.18 & 0.17 & 0.31 & 0.32 & 0.34 \\
\hline $\mathbf{Y b}$ & 1.14 & 1.3 & 1.11 & 1.96 & 2.23 & 2.31 \\
\hline Lu & 0.16 & 0.19 & 0.16 & 0.29 & 0.3 & 0.32 \\
\hline
\end{tabular}




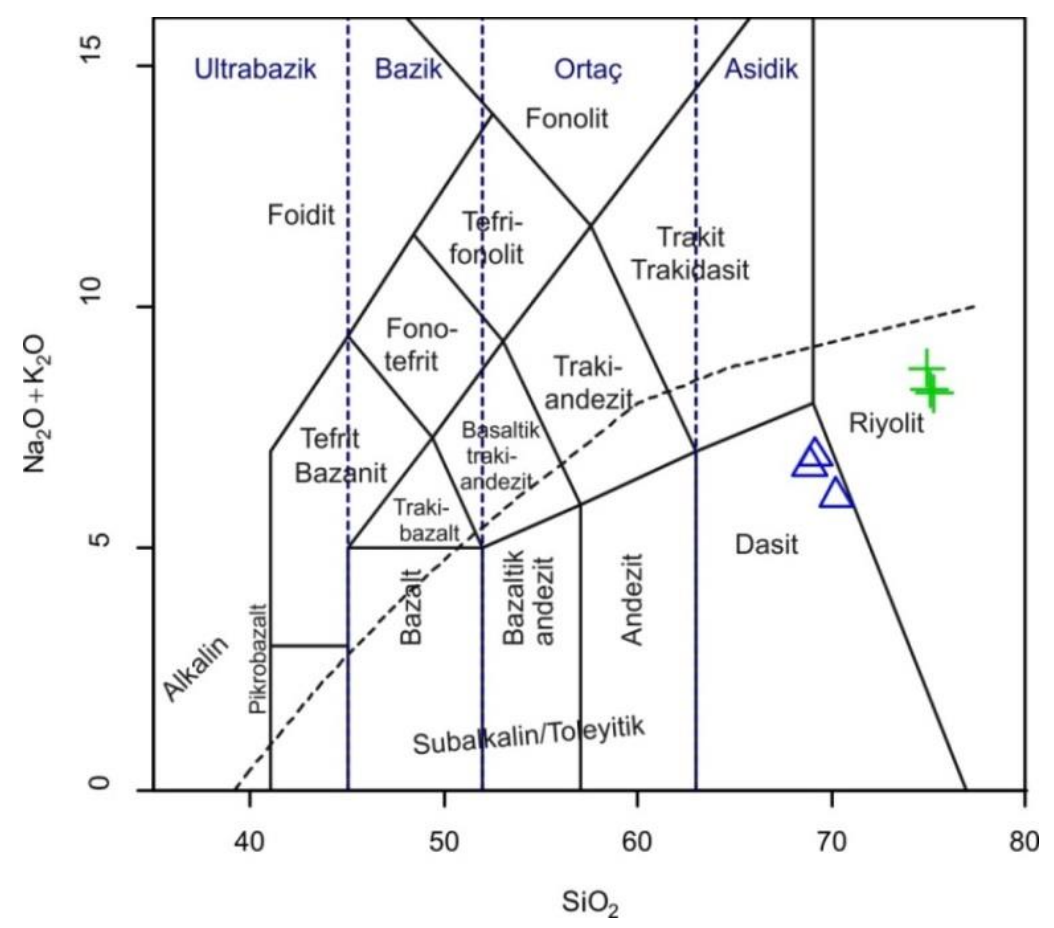

Şekil 3. Incelenen volkanitlerin Le Bas vd. [35]'ye ait $\mathrm{SiO}_{2}-\mathrm{Na}_{2} \mathrm{O}+\mathrm{K}_{2} \mathrm{O}$ diyagramı

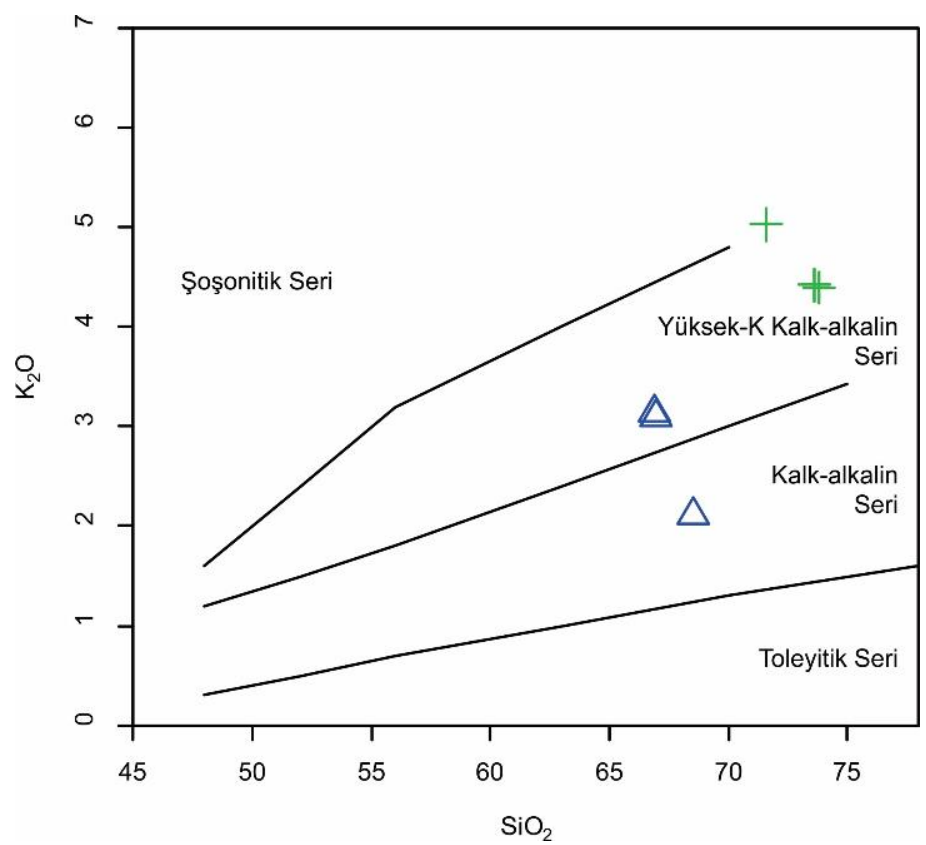

Şekil 4. Incelenen volkanitlerin $\mathrm{SiO}_{2}-\mathrm{K}_{2} \mathrm{O}$ diyagramı [36], (Semboller Şekil 3 ile aynıdır) 

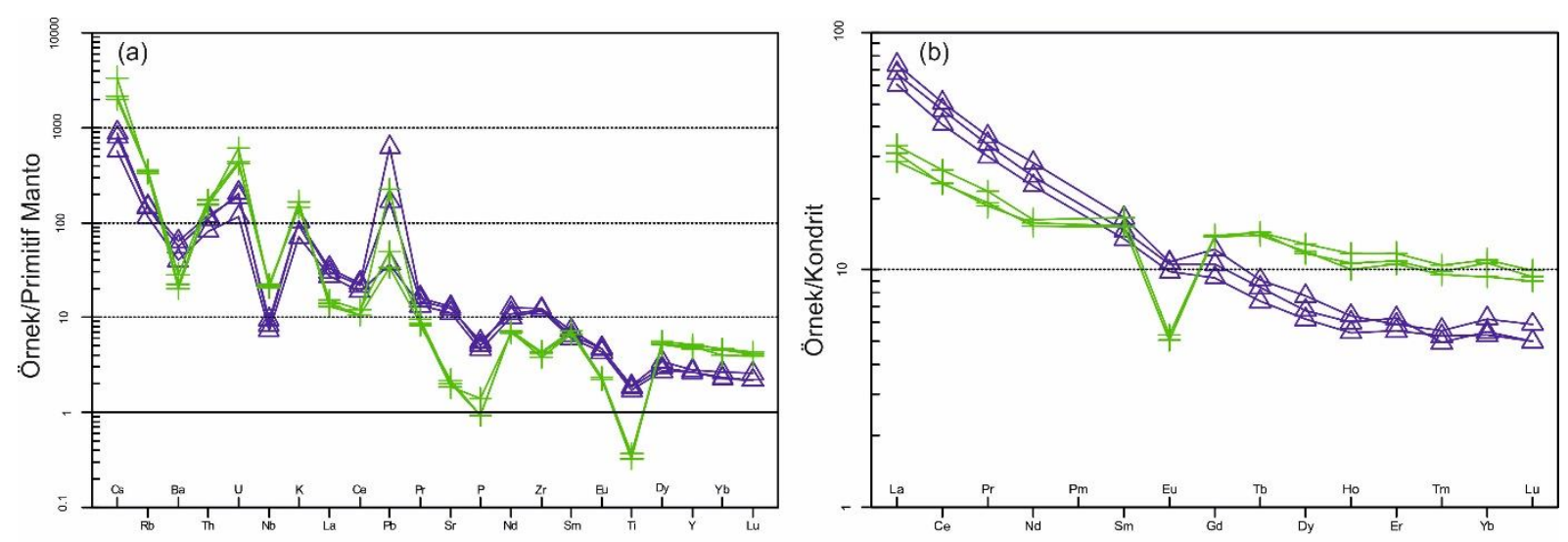

Şekil 5. Incelenen volkanitlerin (a) primitif mantoya normalize edilmiş çoklu element değişim diyagramı [37],(b) kondrite normalize edilmiş nadir toprak element değişim diyagramı[38], (Semboller Şekil 3 ile aynıdır)
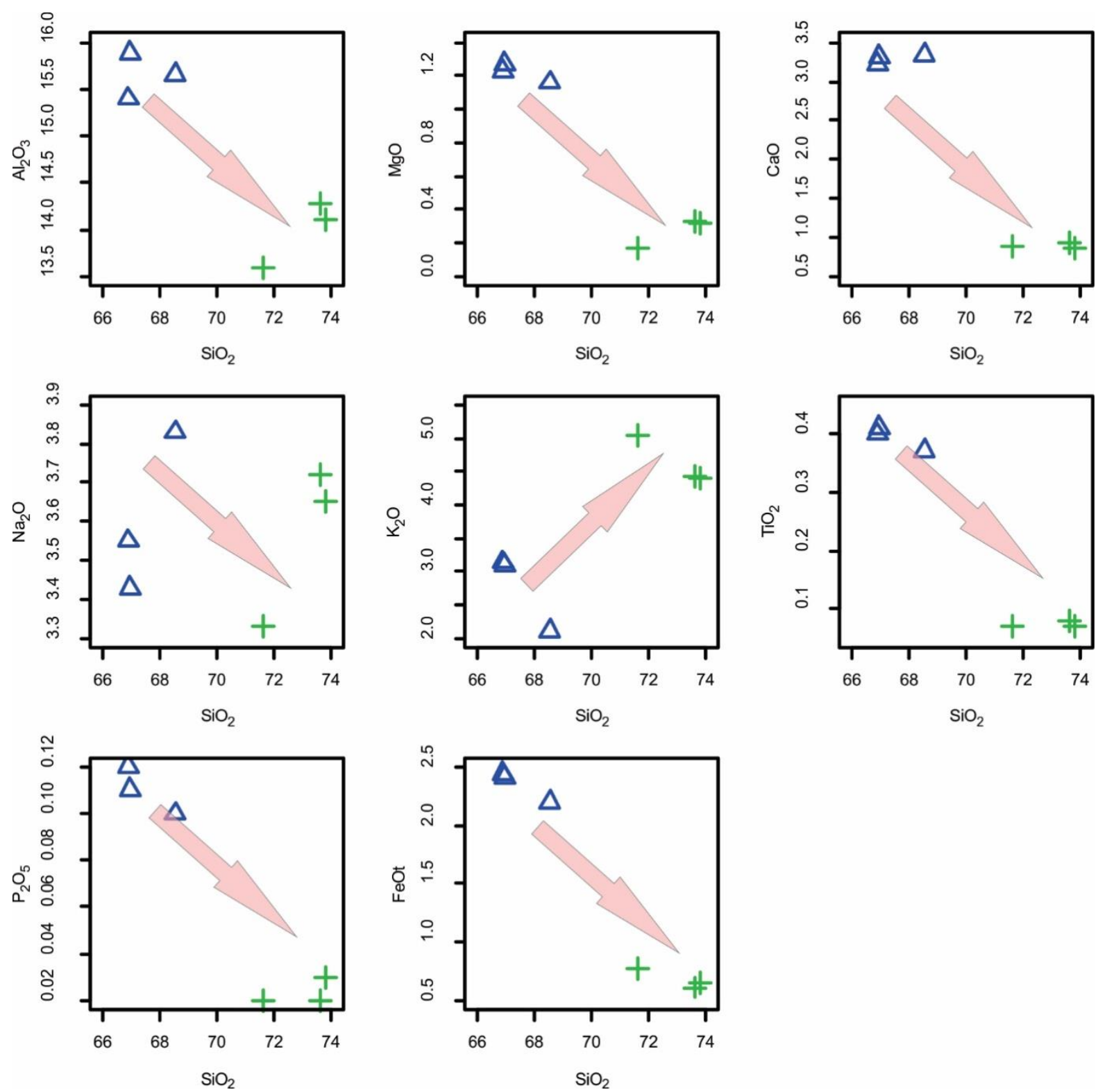

Şekil 6. Incelenen volkanitlerin $\mathrm{SiO}_{2}$ 'ye karşı çizilmiş ana oksit değişim diyagramları, (Semboller Şekil 3 ile aynidir) 

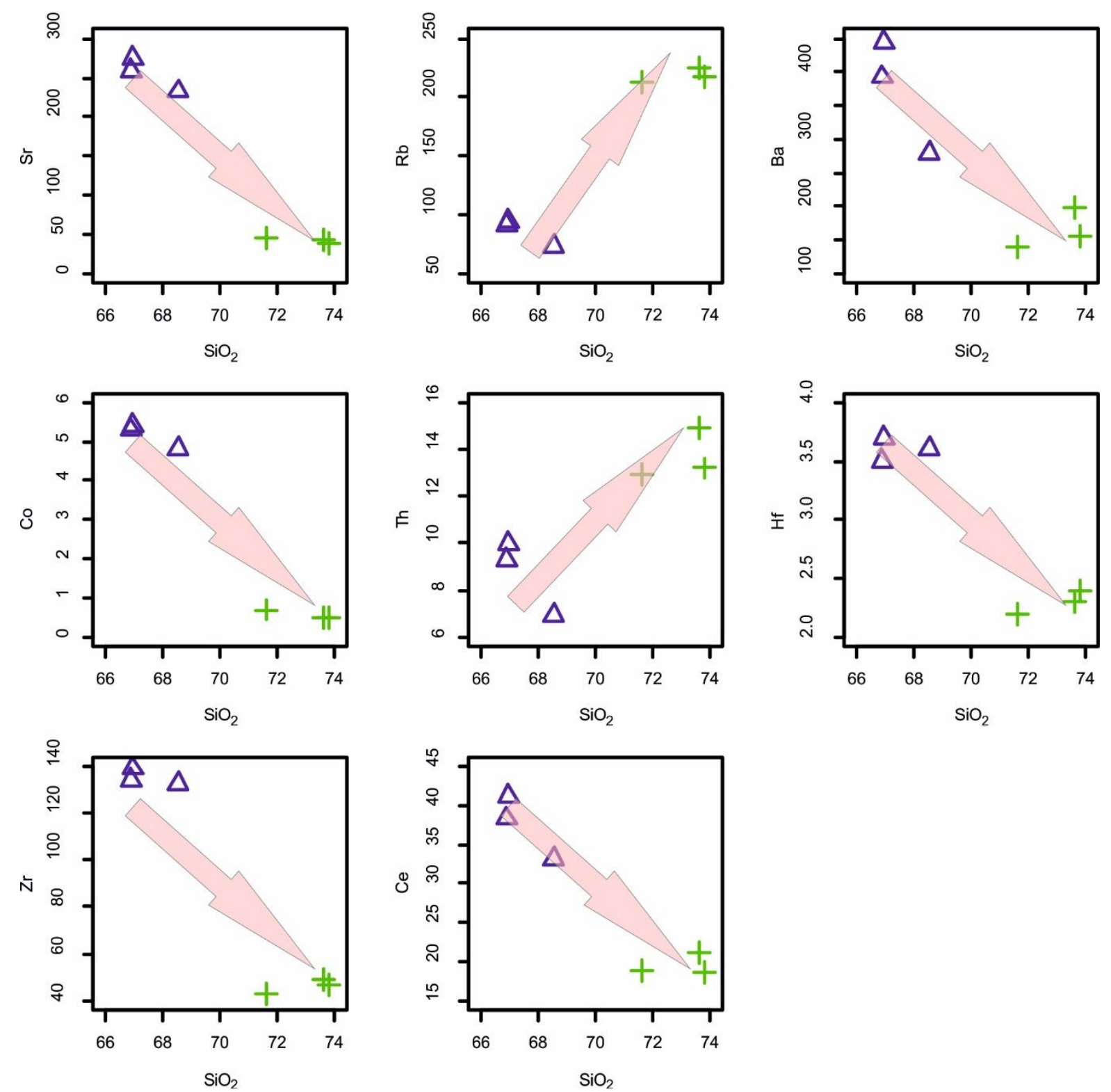

Şekil 7. Incelenen volkanitlerin SiO2 ye karşı çizilmiş iz element değişim diyagramları, (Semboller Şekil 3 ile aynidır)

\section{TARTISMMA}

\section{A. MAGMA KAYNAK ALANI}

Primitif mantoya normalize edilmiş iz element desenlerine göre LILE'ler, yüksek alan HFSE'lere zenginleşme göstermektedir (Şekil 5a). Yitim ile ilişkilendirilen negatif $\mathrm{Nb}, \mathrm{P}$, Ti ve pozitif $\mathrm{Pb}$ anomalisi gibi özellikler Geç Kretase'deki yitime bağlı olarak okyanusal kabuktan ayrılan solüsyonlar tarafından metasomatize edilmiş bir mantodan kaynaklandığı düşünülmektedir. Bunun yanında, bu tür negatif anomaliler, kıtasal kabuğun $\mathrm{Nb}$ bakımından fakir olması nedeniyle kabuksal kirlenmeden de kaynaklanabilir. LILE'deki zenginleşme, dalan levhadan kaynaklanan akışkanlar veya ergiyiklerin yukarı (dalan levhanın üstündeki manto kamasına doğru) taşınması ve manto kamasını metasomatize etmesinin bir sonucu olduğu belirtilmektedir [39]-[43]. Manto metasomatizması, üst mantodaki iz element zenginleşmesini ifade etmek için kullanılır.Bu zenginleşme mantonun göreli olarak daha alt kısmından gelen $\mathrm{H}_{2} \mathrm{O}$ ve $\mathrm{CO}_{2}$ gibi uçucu bileşenler ve LILE açısından zengin akışkanların/eriyiklerin, 
üst düzeylerdeki katı manto kayaçları ile tepkimesi sonucu ortaya çıkmaktadır [44-45].HFSE'deki fakirleşme ise, bu elementlerin dalan levhadaki mineral fazlarında tutulması ile gerçekleşmektedir [23]. İncelenen volkanitler kondrite karşı çizilmiş değişim diyagramları incelendiğinde, HNTE'lerce ( $\mathrm{La}, \mathrm{Ce}, \mathrm{Pr}, \mathrm{Nd})$ zenginleşme, ANTE'ce (Er, Tm, Yb, Lu) değerleri yatay ve yataya yakın dağılımlara sahip oldukları görülmektedir (Şekil 5b). Buna göre, magmatik farklılaşma süreçleri veya kısmi ergime sırasında HNTE'lerin sıvı fazı tercih ettikleri söylenebilir.HNTE bakımından zenginleşme, yitim sonucu dalan levhanın kaynağa olan katkısı ile veya kabuksal bileşenlerin etkisiyle de gerçekleşebilir.İncelenen örneklerde belirgin negatif Eu anomalileri görülmesi incelenen volkanitlerin fraksiyonlanmasında plajiyoklas önemli bir yer tutmaktadır $\left(\mathrm{Eu} / \mathrm{Eu}^{*}=0.35-0.85\right)$. Huang vd. [46] $\mathrm{La} / \mathrm{Nb}$ oranının düşük olmasının kıta içi zenginleşme, yüksek olmasının yitim zenginleşmesinin etkili olduğunu ileri sürmüştür. İncelenen dasitlerin $\mathrm{La} / \mathrm{Nb}$ oranının 3.4-3.60 arasında değişmesi yitim zenginleşmesi, riyolitlerin ise $\mathrm{La} / \mathrm{Nb}$ oranının $0.6-0.64$ arasında değişmesi kıta içi zenginleşmenin etkili olduğunu göstermektedir.

İncelenen volkanitler $\mathrm{La} / \mathrm{Yb}-\mathrm{Pb} / \mathrm{Ce}$ diyagramında örneklerin gelişiminde dalan okyanusal kabuktan ayrılan solüsyonlar (yitim dilimi kökenli akışkanlar = slab fluids) tarafından metasomatize edilmiş mantonun etkisi görülmektedir. Defant vd. [47], Maury vd. [48], Sajona vd. [49] ve Martin vd. [50] yitim dilimi kökenli ergiyikler tarafindan metasomatize olmuş manto kamasından türeyen magmaların $\mathrm{Nb}$ içeriklerinin $(7 \mathrm{ppm}<\mathrm{Nb}<20 \mathrm{ppm})$ yüksek olduğunu ileri sürmektedirler. Çalışma alanındaki volkanitlerin $\mathrm{Nb}$ içerik ortalamaları $10.6 \mathrm{ppm}$ olması bu kayaçlarınyitime bağlı olarak okyanusal kabuktan türeyen çözeltiler tarafından metasomatize edilmiş bir mantodan kaynaklanmış olabileceği görüşünü desteklemektedir.

\section{B. FRAKSIYYONEL KRISTALLEŞME VE KABUKSAL KİRLENME}

$\mathrm{SiO}_{2}$ 'ye karşı ana ve iz element değişim diyagramlarının çoğunlukla iyi korelasyon vermeleri, volkanitlerin gelişiminde ayrımlaşmanın önemli rol oynadığına işaret etmektedir İncelenen volkanitlerin $\mathrm{SiO}_{2}$ 'ye karşı çizilmiş ana oksit ve iz element değişim diyagramlarından da görülebileceği gibi $\mathrm{SiO}_{2}$ 'deki artı̧̧la birlikte $\mathrm{Al}_{2} \mathrm{O}_{3}, \mathrm{MgO}, \mathrm{CaO}, \mathrm{Na}_{2} \mathrm{O}, \mathrm{TiO}_{2}, \mathrm{P}_{2} \mathrm{O} 5$ ve FeOt azalırken, $\mathrm{K}_{2} \mathrm{O}$ artış yönünde bir yönelim göstermektedir (Şekil 6). Bu şekildeki pozitif ve negatif korelasyonlar fraksiyonel kristalleşme süreci ile ilişkilidir. $\mathrm{Na}_{2} \mathrm{O}^{\prime}$ de gözlenen azalmalar, sodik plajiyoklazların fraksiyonlanması ile; $\mathrm{MgO}$ ve $\mathrm{Al}_{2} \mathrm{O}_{3}$ 'deki azalmalar, biyotit fraksiyonlanması ile; $\mathrm{CaO}$ ve $\mathrm{MgO}$ deki negative yönelimler piroksen fraksiyonlanması ile; $\mathrm{Fe}_{2} \mathrm{O}_{3}$ ve $\mathrm{TiO}_{2}$ 'de ki negatif yönelimler ise amfibol ve Fe-Ti oksit fraksiyonlanması ile; $\mathrm{P}_{2} \mathrm{O}_{5}$ teki azalmalar apatit fraksiyonlanması ile ilişkilidir. $\mathrm{SiO}_{2}$ ile artışla birlikte $\mathrm{Sr}, \mathrm{Rb}, \mathrm{Ba}, \mathrm{Co}, \mathrm{Hf}, \mathrm{Zr}$ ve $\mathrm{Ce}$ arasında pozitif; $\mathrm{Rb}$ ve Th arasında ise negatif bir ilişki gözlenmektedir (Şekil 7). Bu durum, klasik fraksiyonel kristalleşme yönelimlerine karşıllik gelmektedir.Sr ve $\mathrm{Ba}$ feldispatların, Co ve Ce piroksen ve biyotitlerin, $\mathrm{Hf}$ ve $\mathrm{Zr}$ zirkonların fraksiyonlanmasıyla ilgilidir. Rb ve Th iyonik yarıçapının K'a yakın olması nedeni ile K'un yerini almakta, fraksiyonel kristalleşme sirasında K-feldispat, biyotit gibi minerallerinin bünyesine girebilmektedir.Fraksiyonel kristalleşme sırasında, bu mineraller daha geç evrelerde kristalleştiğinden, $\mathrm{SiO}_{2}$ ile pozitif bir korelasyon göstermektedir.

Şekil 8' de verilen $\mathrm{Nb} / \mathrm{Y}$ - $\mathrm{Th} / \mathrm{Y}$ diyagramındaki yüksek $\mathrm{Th} / \mathrm{Y}$ ve buna bağlı olarak düşük $\mathrm{Nb} / \mathrm{Y}$ oranı yitim zenginleşmesinin, buna karşın yüksek $\mathrm{Th} / \mathrm{Y}$ ve $\mathrm{Nb} / \mathrm{Y}$ oranı ise kıta içi zenginleşmenin bir sonucudur [51]. Buna göre, incelenen volkanik kayaçlara ait tüm örneklerin $\mathrm{Th} / \mathrm{Nb}=1$ değerine yakın değerlerde oldukları gözlenmiştir. Diyagramda örneklerin gösterdiği yönseme, kıta içi zenginleşme ile birlikte asimilasyon-fraksiyonel kristalleşmenin etkisini göstermektedir. Üst kıtasal kabuğun ortalama $\mathrm{Ta} / \mathrm{Zr}$ değeri $0.01 \mathrm{ppm}$ primitif mantonun $\mathrm{Ta} / \mathrm{Zr}$ değeri $0.003 \mathrm{ppm}$ [52] olup incelenen dasitlerin $\mathrm{Ta} / \mathrm{Zr}$ oranı 0.003 pmm-0.05 pmm arasında değişim göstermekte ve üst kıtasal kabuk değerinden düşük $\mathrm{Ta} / \mathrm{Zr}$ değerleri de kabuksal kirlenmeden ziyade primitif mantoya işaret etmektedir. İncelenen riyolitlerin $\mathrm{Ta} / \mathrm{Zr}$ değerleri 0.053-0.057 pmm arasında değişen ve üst kıtasal kabuk değerinden yüksek $\mathrm{Ta} / \mathrm{Zr}$ değerleri de kabuksal kirlenmeye işaret etmektedir. 


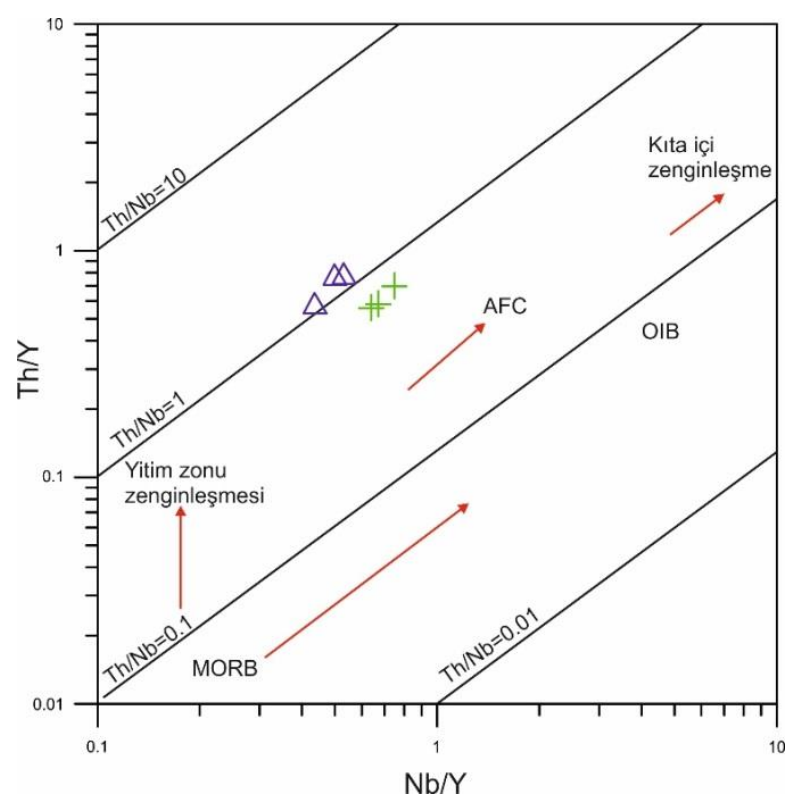

Şekil 8. Incelenen volkanitlere ait $T h / Y-N b / Y$ diyagramı

\section{TEKTONIK ORTAM}

$\mathrm{Ta} / \mathrm{Yb}-\mathrm{Th} / \mathrm{Yb}$ diyagramında [53] incelenen volkanitler, manto dizisine paralel bir hizalama sunmakta, fakat yüksek $\mathrm{Th} / \mathrm{Yb}$ oranlarına sahiptir (Şekil 9). Okyanus ortası sirtındaki bazalt (MORB) mantosuna kıyasla Th'deki zenginleşme, dalma-batma sıvılarının etkisini göstermektedir.Bu durum incelenen volkanitlerin gelişiminde sadece tek bir fraksiyonel kristalleşme farklılaşması geçirmemiş daha büyük olasılıkla çeşitli kontaminasyon süreçlerine maruz kalmıştır.İncelenen volkanitlerin $\mathrm{Th} / \mathrm{Yb}-\mathrm{Nb} / \mathrm{Yb}$ petrojenetik modelleme diyagramında, MORB-okyanus adası bazalt (OIB) dizisinin üzerinde olduğunu ve MORB-OIB alanı ile karşılaştırıldığında önemli $\mathrm{Th}$ / Yb zenginleşmesine sahip olduğunu göstermektedir (Şekil 10).Bu özellik yay sistemlerine özgüdür ve bir yitim bileşeninin önemli bir girdisi ile ilişkili olabilir [43].Örneklerde izlenen yitim-türevli bileşenin katkısını daha önce dalma yoluyla kirlenmiş olan bir litosferik mantonun ergimesine bağlayabiliriz.

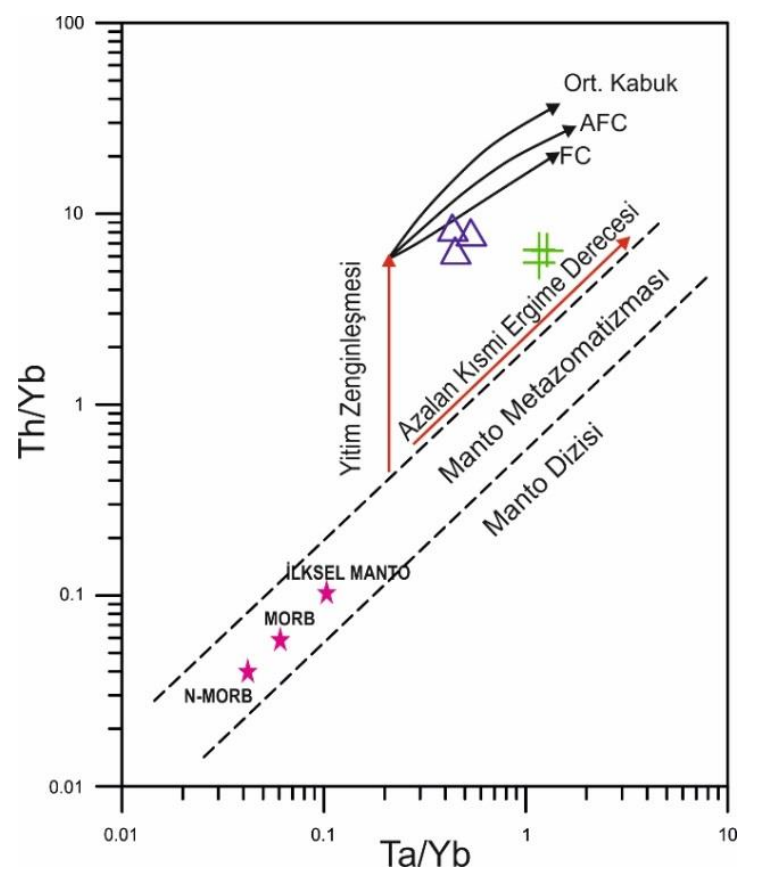

Şekil 9.Incelenen volkanitlere ait Ta/Yb-Th/Yb log - log diyagramı [53] 


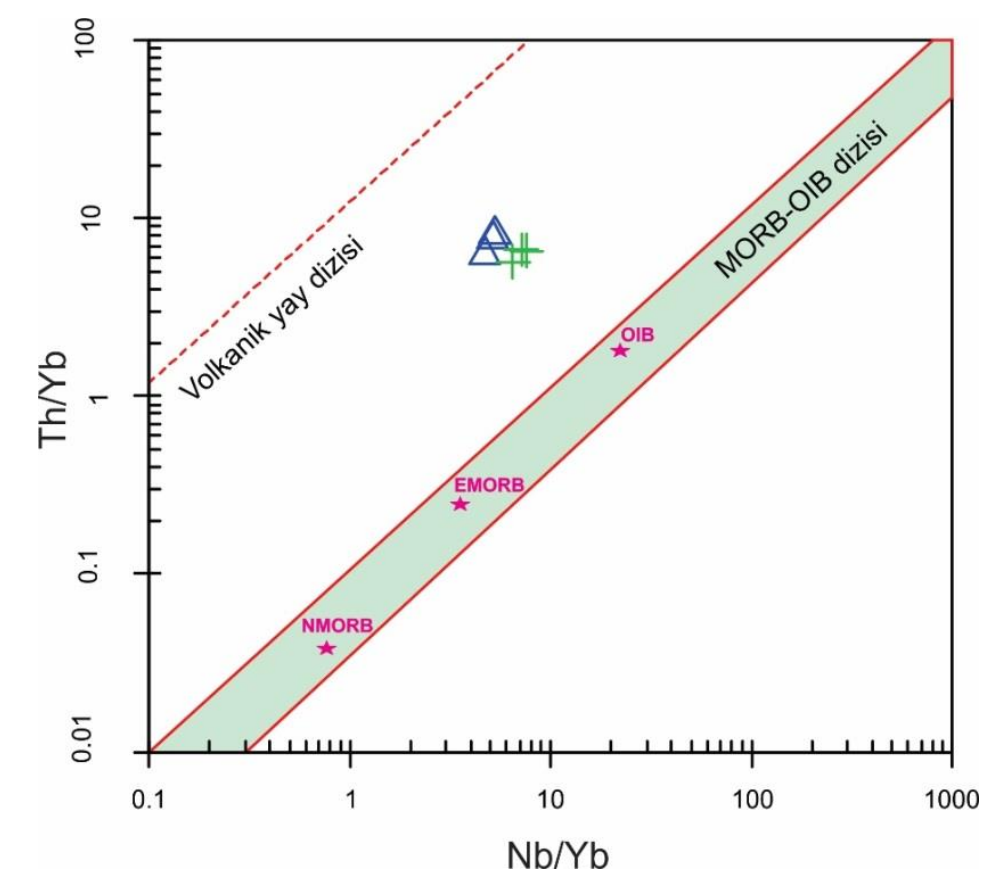

Şekil 10. Incelenen volkanitlere ait $N b / Y b-T h / Y b$ log - log diyagramı [53]

\section{SONUCLAR}

- İnceleme alanındaki Neojen (?) volkanitleri dasit ve riyolit türü kayaçlar ile temsil edilmektedir.

- İncelenen volkanik kayaçlar Malatya metamorfitlerini sıcak dokanakla keserek dayklar halinde yerleşmişlerdir.

- Petrografik verilere göredasitler makroskobik olarak grimsi renklerde görülmekte ve porfirik doku göstermektedir. Bileşimsel olarak \% 35 plajiyoklas, \% 25 kuvars, \% 10 biyotit+amfibol, plajiyoklas+biyotit mikrolitleri ve camsı malzeme içeren hamur malzemesinden oluşmaktadır. Riyolitler bileşimsel olarak \% 15 kuvars, \% 20 sanidin \% 25 plajiyoklas \% 10 biyotit+amfibol ve \% 30 kuvars+plajiyoklas mikrolitleri ve camsı malzeme içeren hamur malzemesinden oluşmaktadır. Makroskobik olarak pembemsi renklerde olup porfirik doku göstermektedir.

- İncelenen dasitlerin $\mathrm{La} / \mathrm{Nb}$ oranının 3.4-3.60 arasında değişmesi yitim zenginleşmesinin, riyolitlerin ise $\mathrm{La} / \mathrm{Nb}$ oranının $0.6-0.64$ arasında değişmesi kıta içi zenginleşmenin etkili olduğunu göstermektedir.

- İncelenen dasitlerin $\mathrm{Ta} / \mathrm{Zr}$ oranı 0.003 pmm-0.05 pmm arasında değişim göstermekte olup kabuksal kirlenmeden ziyade primitif mantoya işaret etmektedir. İncelenen riyolitlerin $\mathrm{Ta} / \mathrm{Zr}$ değerleri 0.053-0.057 pmm arasında değişen ve üst kıtasal kabuk değerinden yüksek $\mathrm{Ta} / \mathrm{Zr}$ değerleri de kabuksal kirlenmeye işaret etmektedir.

- İncelenen kayaçların yitim dilimi kökenli akışkanlar tarafından zenginleşmiş bir manto kaynağından türemiş olabileceği görüşü desteklenmektedir.

TEŞEKKÜR: Bu çalışma Fırat Üniversitesi Bilimsel Araştırma Projeleri tarafindan desteklenmiştir (Proje no: FÜBAP MF16.63). 


\section{KAYNAKLAR}

[1] A. M. C. Şengör and Y. Y1lmaz, "Tethyan evolution of Turkey: a plate tectonic approach," Tectonophysics, vol. 75, pp. 181-241, 1981.

[2] Y. Y1lmaz, "New evidence and model evolution of the southeast anatolian orogen", Geological Society of America Bulletin, vol.105, pp.251-271, 1993.

[3] R. Oberhänsli, O. Candan, R. Bousquet, G. Rimmele, A. Okay and J. Goff, "Alpine high pressure evolution of the eastern Bitlis complex, SE Turkey", Geological Society, London, Special Publications, vol. 340, no.1, pp.461-483,2010.

[4] A. M. C. Şengör, “Türkiye'nin Neotektoniği’nin Esasları,” TJK Konferans Serisi, c. 2, s. 2, ss.1-40, 1980.

[5] F. Şaroğlu, Y. Güner, W. S. F. Kidd, and A. M. C. Şengör, "Neotectonics of Eastern Turkey: New evidence for Crustal shortening a collision zone", EOS Transactions American Geophysical, vol.51, no.17, pp. 360-380, 1980.

[6] J. A. Pearce, J. F. Bender, S. E. De Long, W. S. F. Kidd, P. J. Low, Y. Güner, F. Şaroğlu, Y. Y1lmaz, S. Moorbath, and J. G. Mitchell, "Genesis of collision volcanism in Eastern Anatolia, Turkey" Journal of Volcanology and Geothermal Research, vol.44, no.1-2, pp.189-229, 1990.

[7] M. Keskin, "Magma generation by slab steepening and breakoff beneath a subduction accretion complex: an alternative model for collision- related volcanism in Eastern Anatolia, Turkey",Geophysical Research Letters, vol. 30, pp. 8046-8050, 2003.

[8] M. Keskin, J. A. Pearce, P. D. Kempton, and P. Greenwood, "Magmacrust interactions and magma plumbing in a postcollisional setting: Geochemical evidence from the Erzurum-Kars volcanic plateau, eastern Turkey", In: Dilek, Y. \&Pavlides, S (eds), Postcollisional Tectonics and Magmatism in the Mediterranean Region and Asia,Geological Society of America, Special Paper,vol.409, pp.475505,2006 .

[9] M. Keskin, "Eastern Anatolia: a hotspot in a collision zone without a mantle plume,In: Foulger, G.R., Jurdy, D.M. (Eds.), Plates, Plumes, and Planetary Processes", Geological Society of America Special Paper, vol.430, pp.693-722,2007.

[10] T. Ekici, M. Alpaslan, O. Parlak, and A. Temel, "Geochemistry of the Pliocene basalts erupted along the Malatya-Ovacik fault zone (MOFZ), eastern Anatolia, Turkey: implications for source characteristics and partial melting processes", Chemie der Erde, 67, 201-212, 2007.

[11] T. Ekici, M. Alpaslan, O. Parlak, and A.Uçurum, "Geochemistry of the Middle Miocene collision-related Yamadağı (Eastern Anatolia) Calc-alkaline Volcanics, Turkey", Turkish Journal of Earth Sciences, vol.18, pp.511-528, 2009.

[12] A.Önal, D. Boztuğ, M. Arslan, T. L. Spell, and S. Kürüm, "Petrology and ${ }^{40} \mathrm{Ar}-{ }^{39} \mathrm{Ar}$ age of the bimodal Orduzu Volcanics (Malatya) from the western end of the eastern Anatolian Neogene volcanism, Turkey," Turkish Journal of Earth Sciences, vol.17, pp.85-109.2008.

[13] S. Kürüm, A. Önal, D. Boztuğ, T. Spell, and M. Arslan, “ ${ }^{40} \mathrm{Ar} /{ }^{39} \mathrm{Ar}$ age and geochemistryof the post-collisionalMiocene Yamadağ volcanics in the Arapkir area (Malatya Province), eastern Anatolia, Turkey”,Journal of Asian Earth Sciences, vol.33, pp.229-251, 2008. 
[14] V. Oyan, M. Keskin, V. A. Lebedev, A. V. Chugaev, and E. V. Sharkov, "Magmatic evolution of the early Pliocene Etrüsk stratovolcano, eastern Anatolian collision zone, Turkey," Lithos, vol. 256257, pp. 88-108,2016.

[15] T. Ekici,"Collision-related slab break-off volcanism in the Eastern Anatolia, Kepez volcanic complex (TURKEY)”, Geodinamica Acta, vol. 28, no. 3, pp. 223-239, 2016.

[16] P. Di Giuseppe, S. Agostini, M. Lustrino, Ö. Karaoğlu, M. Y. Savaşçın, P. Manetti, and E.Y. Ersoy, "Compression to strike-slip tectonics shift as revealed by Miocene-Pleistocene volcanismwest of the Karliova triple junction (East Anatolia)," Journal of Petrology, vol. 58, pp. 2055-2087. 2017.

[17] P. Di Giuseppe, S. Agostini, G. Di Vincenzo, P. Manetti, M.Y. Savaş̧̧ı, and S. Conticelli. "From subduction to strike slip-related volcanism: insights from $\mathrm{Sr}, \mathrm{Nd}$, and $\mathrm{Pb}$ isotopes and geochronology of lavas from Sivas-Malatya region, Central Eastern Anatolia," vol. 110, pp. 849-874, 2021.

[18] A. Koçaarslan and E. Y. Ersoy, "Petrologic evolution of Miocene-Pliocene mafic volcanism in the Kangal and Gürün basins (Sivas- Malatya), central east Anatolia: evidence for Miocene anorogenic magmas contaminated by continental crust," Lithos, vol.310-311, pp. 392-408, 2018.

[19] W.K.Schleiffarth, M.H.Darin, M.R.Reid, andP.J.Umhoefer, "Dynamics of episodic Late Cretaceous-Cenozoic magmatism across Central to Eastern Anatolia: New insights from anextensive geochronology compilation" Geosphere, vol.14, no.5, pp.1-19, 2018.

[20] A. Aktağ, A. Öztüfekçi Önal, and K. Sayit, "Geochemistry of the post-collisional Miocene mafic Tunceli Volcanics, Eastern Turkey: Implications for the nature of the mantle source and melting systematics" Chemie der Erde, vol.79,pp.113-129, 2019.

[21] S. Kürüm, T. Baykara, "Geochemistry of post-collisional Yolçatı (Bingöl) volcanic rocks in Eastern Anatolia, Turkey”, Journal of African Earth Science, vol.161, 103653, 2020.

[22] Ö. Karaoğlu,F. Gülmez,G, Göçmengil M, Lustrino, P. Di Giuseppe, and P. Manetti, M.Y. Savaşçın, and S. Agostini, "Petrological evolution of Karlıova-Varto volcanism (Eastern Turkey): magma genesis in a transtensional triple-junction tectonic setting", Lithos, pp.364-365, 105524,2020.

[23] E. Yiğitbaş, "Engizek dağı (Kahramanmaraş) dolayındaki tektonik birliklerin petrolojik incelenmesi”, Doktora Tezi, İstanbul Üniversitesi Fen Bilimleri Enstitüsü,İstanbul, Türkiye, 1989.

[24] A. Önal, "Polat-Beğre (Doğanşehir) çevresindeki magmatik kayaçların petrografik ve petrolojik özellikleri”, Doktora Tezi, Frrat Üniversitesi Fen Bilimleri Enstitüsü, Elazı̆̆g, Türkiye, 1995.

[25] A. Önal, M. Altunbey, "Dedeyazı-Çavuşlu (Doğanşehir-Malatya) yöresindeki skarn oluşumlar ve ilişkili demir cevherleşmeleri”, Türkiye Jeoloji Bülteni, c.1, ss.15-27, 1999.

[26] F. Karaoğlan, "Günedoğru-Beğre (Doğanşehir-Malatya) Arasında Yüzeyleyen Tektonomagmatik Birimlerin Petrografisi ve Jeokimyası", Yüksek Lisans Tezi, Çukurova Üniversitesi Fen Bilimleri Enstitüsü, Adana, Türkiye, 2005.

[27] E. Yazgan, R. Chessex, "Geology and tectonic evolution of the southeastern Taurides in the region of Malatya", Turkish Assoc. Petrol Geol.,c.3, s.1, ss.1-42, 1991.

[28] Y. Y1lmaz, "New evidence and model on the evolution of the Southeast Anatolian orogeny", Geological Society of the America Bulletin, vol.105, pp.251-271, 1993. 
[29] M. Önal ve A.M. Gözübol, "Çat Baraji isale tünelinin mühendislik jeolojisi ve kaya mekanigi incelemesi ve Malatya-Çelikhan yöresinin jeolojisi”, Tübitak Projesi Raporu,ss.647, 1986.

[30] A. Önal ve M. Beyarslan, "Doğanşehir (Malatya) civarındaki ofiyolitik kayaçların jeolojik ve petrografik özellikleri”, Selçuk Üniversitesi Mühendislik-Mimarlık Fakültesi Dergisi, c. 16, s. 2, ss. 66-75, 2001.

[31] F. Karaoğlan, O. Parlak, A. Robertson, M. Thöni, U. Klötzli, F. Koller, and A.I. Okay, "Evidence of Eocene high-temperature/high-pressure metamorphism of ophiolitic rocks and granitoid intrusion related to Neotethyan subduction processes (Dogansehir area, SE Anatolia)," 7th International Symposium on Eastern Mediterranean Geology, , Adana, Turkey, pp.249-272, 2010.

[32] M. A. Ertürk, “Maden Karmaşığı’nın (Doğu Toroslar-Türkiye) petrolojik özellikleri”, Doktora Tezi, Fırat Üniversitesi Fen Bilimleri Enstitüsü, Elazığ, Türkiye, 2016.

[33] M. A. Ertürk, M. Beyarslan, S.L. Chung, and T. Lin, "Eocene magmatism (Maden Complex) in the Southeast Anatolian Orogenic Belt: Magma genesis and tectonic implications" Geoscience Frontiers, vol.9, pp.1829-1847, 2018.

[34] M.T.A, "1/500.000 ölçekli Türkiye Jeoloji Haritası", Maden Tetkik ve Arama Genel Müdürlüğ̈̈, Ankara, Türkiye, 2002.

[35] M.J. Le Bas, R.W. Le Maitre, A. Streckeisen, and B. Zanettin, "A chemical classification of volcanic rocks based on the total alkali-silica diagram", J. Petrology, vol. 27, no. 3, pp.745-750, 1986.

[36] A. Peccerillo, S.R. Taylor, "Geochemistry of Eocene calcalkaline volcanic rocks from the Kastasmonu area, north Turkey", Contrib. Miner. Petrol, vol. 58, pp. 63-81, 1976.

[37] S. Sun and W.F. McDonough, "Chemical and isotopic systematic of oceanic basalts. Implications for mantle compositional processes. In: Saunders, A.D., Norry, M.J.(Eds.), Magmatism in the Ocean Basins", Special Publication Geological Society of London, vol. 42, pp. 313-345, 1989.

[38] W.V. Boynton, "Geochemistry of rare earth elements: meteorite studies", In: Henderson, P. (Ed.), Rare Earth Element Geochemistry. Elsevier, New York, pp.63-114, 1984.

[39] J. A. Pearce, "Trace Element Characteristics of Lavas from Destructive Plate Boundaries. In: Thorpe, R.S. (eds) Andesites, Orogenic Andesites and Related Rocks", J. Wiley and Sons, pp.525$548,1982$.

[40] M. T. McCulloch and J. A. Gamble, "Chemical and geodynamic constraints on subduction zone magmatism” Earth and Planetary Science Letters, vol.102, pp.358-374, 1991.

[41] W.F. McDonough, "Geochemical and isotopic systematics of continental lithospheric mantle. In: kimberlites, Related Rock and Mantle Xenoliths", Meyer, H.O.A. and Leonardos, O. H. (Ed.).Companhian de Pequisa de Recursos Minerais, Rio de Janeiro, no.1, pp.478-485, 1991.

[42] M. F. Thirwall, T. E. Smith, A. M. Graham, N. Theodorou, P. Hollings, J. P. Davison and R.J. Arculus, "High field strength element anomalies in arc lavas: source or Process" Jour. Petrology, vol.35, pp.819-838, 1994.

[43] J. A. Pearce and D.W. Peate, "Tectonic implications of the composition of volcanic arc magmas" Annual Review of Earth and Planetary Sciences, vol.23, pp.251-285, 1995. 
[44] M. A. Menzies, "Mantle ultramafic xenoliths in alkaline magmas: evidence for mantle heterogeneity modified by magmatic activity", In: C.J.Hawkesworth and M.J.Norry (Editors), Continental Basalts and Mantle Xenoliths, Shiva, Nantwich, pp.92-110, 1983.

[45] S. J. G. Galer and R. K., O'Nions, "Residence time of thorium, uranium and lead in the mantle with implications for mantle convection", Nature (London), vol.316, pp.778-782, 1985.

[46] Y. Huang, C. Hawkesworth, I. Smith, P. van Calsteren, and P. Black, "Geochemistry of late Cenozoic basaltic volcanism in Northland and Coromandel, New Zealand: implications for mantle enrichment processes", Chem. Geol.,vol.164, no.15, pp.219-238, 2000.

[47] M. J. Defant, T. E. Jackson, M. S. Drummond, J. Z. De Boer, H. Bellon, M. D. Feigenson, R. C. Maury, and R. H. Stewart, "The geochemistry of young volcanism throughout western Panama and southeastern Costa Rica: an overview", Journal of the Geological Society of London, vol.149, pp.569$579,1992$.

[48] R. C. Maury, F.G., Sajona, M. Pubellier, H, Bellon, and M.J. Defant, "Fusion de la croûte océanique dans les zones de subduction/collision récentes: L'exemple de Mindanao (Philippines)", Bull. Soc. Géol., France, vol.167, pp.579-595, 1996.

[49] F.G. Sajona, R.C. Maury, H. Bellon, J. Cotton, and M. Defant, "High field strength element enrichment of Pliocene-Pleistocene island arc basalts, Zamboanga Peninsula, Western Mindanao (Philippines)", Journal of Petrology,vol.37, no.3, pp.693-726, 1996.

[50] H. Martin, R.H. Smithies, R. Rapp, J.-F. Moyen, and D. Champion, “An overview of adakite, tonalite-trondhjemite granodiorite (TTG), and sanukitoid: Relationships and some implications for crustal evolution", Lithos, vol.79, pp.1-24, 2005.

[51] C. Deniel, E. Aydar, and A. Gourgaud, "The Hasan Dagi stratovolcano (Central Anatolia, Turkey): evolution from calc-alkaline to alkaline magmatism in a collision zone" J. Volcanol. Geotherm. Research,vol.87, no.1-4, pp.275-302, 1998.

[52] S.R. Taylor, S.M. McLennan, "The Continental Crust: its Composition and Evolution", Blackwell Scientific Publication, pp.312, Oxford, 1985.

[53] J.A. Pearce, "Geochemical fingerprinting of oceanic basalts with applications to ophiolite classification and the search for Archean oceanic crust", Lithos, vol.100,no.1-4, pp.14-48, 2008. 